obtained by Draper's son, Henry, who was in his own right the leader of stellar photography in America. Tho photograph made on Sept. 30, 1880, was given 57 minutes of exposure. In March 1881 a better photograph was made by Henry Draper from an exposure of 104 minutes, and on Mar. 14, 1882 (more than two months after the death of $\mathbf{J} o \mathrm{hn}$ W. Draper), a romarkably successful exposure of 137 minutes was made, which showed stars of the 14.7 magnitude of Pogson's scale--stars invisible to the eye. Henry Draper also obtained many excellent photographs of the spectrum of the nebula in Orion. Unfortunately, Henry Draper died suddenly on Nov. 20 of the same year at the age of forty-five.

The reference in the Calendar to the first astronomical photograph undoubtedly means the daguerreotype of the moon made by John W. Draper in 1840 after an exposure of 20 minutes a representation about an inch in diameter. Daguerre had attempted the feat but without success. John W. Draper experimented in photographing the solar diffraction spectrum on paper before the daguerreotypo process was invented, but he did not know how to develop and fix his image, until Daguerre, Talbot, and Herschel worked out their devcloping and fixing processes. Herschel made the first useful photograph of the solar spectrum in 1840 ; Draper did not succeed in this until 1842.

For some time I have been anxious to learn the true evaluation of John W. Drapex's place in science. He was a man of such varied interests and was au courant with so many scientific developments that it is difficult to gauge his status. For example, thirteen years before Kirchhoff published his celebrated memoir on the relations between the coefficient of emission and absorption of bodies for light and heat, Draper had arrived at some of these same facts non-mathematically. There is no doubt that Draper contributed importantly to the advancement of knowledge of radiant energy. Just how much credit is due to him for his varied researches is the quostion.

Now York University, Nov. 30.

\section{A Theory of the Upper Atmosphere and Meteors.}

THere seems to be a factor omitted by Mr. Maris in the second paragraph of his letter in NATURE (Dec. 10, p. 839) which may modify somewhat the figures he gives. If the constituents of the atmosphere were uniformly mixed at all altitudes and then left fre $\theta$ from convection currents, there would be a partial separation into lighter and heavier particles undoubtedly, but the level reached by the diffusing gases would be conditioned by three factors.

'L'hese will be realised roadily if wo remember that the earth is, in fact, a huge centrifuge and (neglocting convection currents, together with the steady flow into space of some of the lightest particles) the equilibrium position of any constituent depends on (1) gravity, (2) centrifugal force (if I may be pardoned for using such an old-fashioned expression), and (3) osmotic pressure, (2) is small compared to (1), and our centrifugo is therefore one in which the heavier particles converge inwards, but this move. ment is arrested by (3) just as in an ordinary centrifuge. Unfortunately, so far as I am aware, the osmotic pressure of a mixture of gases has not been determined ; I would, however, suggest that if the 'optical centrifuge' described by me (NATURE, Dec. 10, p. 840) were charged with a mixture of argon and hydrogen, some light might be thrown on the subject.

Berkeley Castle, Gloucestershire.

Berkeley.

No. 3035, Vot. 120]
Further Hominid Remains of Lower Quaternary Age from the Chou Kou Tien Deposit.

A'r a meoting of the Geological Society of China, held on Dec. 2, 1927, announcement was made of the discovery of a lower molar hominid tooth in the cave deposit at Chou Kou Tien, near Peking, The new specimen was obtained close to the site from which the first hominid teeth from this locality were recovered and in the same stratum of the deposit (NATuRe, Nov. 20, 1926, p. 733). This deposit, which at first was thought to be Upper Pliocene, is now known to be basal Lower Quaternary in age (very early Pleistocene). The find was made on Oct. 16 by Dr. Birger Bohlin, palæontologist attached to the Geological Survey of China. Mr. C. Li, geologist from the Survey, and Dr. Bohlin have been in charge of the extensive excavations on this important site, which have been carried on during the past season by the Geological Survey in co-operation with the Department of Anatomy of the Peking Union Medical College.

The tooth is a relatively unworn and perfectly preserved lower permanent molar, having incompletely formed root tips, and evidently from an individual in the stage of development represented by that of an eight year old modern European child. The general morphology of this specimen leaves no room for doubt as to its hominid status, and it evidently was derived from the same jaw as that from which came the lower premolar tooth discovered last year by Dr. O. Zdansky. A full description of the latter specimen and of the associated worn upper molar has been published this year by Dr. Zdansky (Bull. Geol. Soc. China, vol. 5, No. 3).

Evidence of a convincing nature points to a close mutual relationship between the two individuals, adult and immature, represented by the teeth recovered from the Chou Kou 'T'ien deposit. The newly discovered specimen displays in the details of its morphology a number of interesting and unique characters, sufficient, it is believed, to justify the proposal of a now hominid genus Sinanthropus, to bo represented by this material. A complete and fully illustrated report on this new specimen is now in press, and will be published early in December in Series D, Paloontologia Sinica, vol. 7, Fasc. 1.

Department of Anatomy,

Peking Union Medical College, Peking, China Nov, 24.

The Publications of the Royal Society.

IT would be a pity if - as, of course, cannot be intended-the remarks in the leading article of Dec. 17 were taken, among an uninstructed public, to imply some disparagement of the scientifie quality of the output of the Cavendish Laboratory in proportion to its extent. In the present avalanche of theories of atomic processes and radiation, what appears to be necessary rnore than ever is precise and informed experiment in this complex and elusive domain. Where are we likely to secure these idcals if not in a company where all the practical experience of all the ages of radio-activity is concentrated ? At any rate, it may be permitted to record the judgment of one outside student of current physioal literature, that it is not there that the fault, if any, is to be located.

Cambridge,

Joseph Larmor.

Dec. 19 , 